Western University

Scholarship@Western

Physical Therapy Publications

Physical Therapy School

4-1-2019

\title{
Validity of the Early Activity Scale for Endurance and the 6-Minute Walk Test for Children With Cerebral Palsy.
}

Alyssa LaForme Fiss

Lynn Jeffries

Allison Yocum

Sarah Westcott McCoy

On Track Study Team

Follow this and additional works at: https://ir.lib.uwo.ca/ptpub

Part of the Physical Therapy Commons

Citation of this paper:

Fiss, Alyssa LaForme; Jeffries, Lynn; Yocum, Allison; Westcott McCoy, Sarah; and On Track Study Team, "Validity of the Early Activity Scale for Endurance and the 6-Minute Walk Test for Children With Cerebral Palsy." (2019). Physical Therapy Publications. 50.

https://ir.lib.uwo.ca/ptpub/50 


\section{Abstract}

Purpose: This study aimed to: 1) describe the 4-item Early Activity Scale for Endurance (EASE) scores and Six-Minute Walk Test (6MWT) distances of children with cerebral palsy (CP) by functional ability level, sex, and age; and 2) examine the convergent validity of the EASE to the 6MWT. Methods: 708 children with CP (18-months to 12-years), GMFCS Levels I-V, completed the EASE, and 376 of the study participants, (3-12-years), GMFCS Levels I-III, also completed the 6MWT. Results: Children with CP present with variations in EASE scores and 6MWT distances based on GMFCS level and, to a lesser extent, age. The EASE and 6MWT demonstrate a statistically significant but low, positive correlation. Conclusions: Understanding the relationship between these outcomes and GMFCS levels and age, assists clinicians in establishing plans of care targeted at improving endurance for activity and functional walking capacity for children with CP.

\section{Background}

Children with cerebral palsy (CP) typically present with lower levels of daily physical activity than children who are typically developing. ${ }^{1,2}$ Physical activity is defined as, "any bodily movement produced by skeletal muscles that requires energy expenditure." ${ }^{1(p .126)}$ For children with $\mathrm{CP}$, impairments in muscle tone, postural control, strength, range of motion, and coordination may contribute to low levels of physical activity, poor endurance, and limitations in functional mobility. ${ }^{4}$ Specifically, reduced endurance has been identified as a main factor in decline in walking ability as children with cerebral palsy age, ${ }^{6-8}$ and may impact a child's ability to fully participate in home, school, and community activities. ${ }^{9}$ Because of these trends, it is important for rehabilitation providers to assess endurance of children with $\mathrm{CP}$, to track changes over time, and attempt to mediate further functional decline. Clinicians rely on readily available, easily administered measures to establish a baseline and measure change over time. The Early 
Activity Scale for Endurance (EASE) $)^{10,11}$ ( 4 and 10 item versions) and six-minute walk test $(6 \mathrm{MWT})^{12}$ are designed for these purposes.

The 4-item EASE is a short, parent completed measure of perceived endurance for activity for children. The four items are: 1) My child's physical activity level is similar to other children his or her age, 2) My child has a high physical energy level and rarely needs to take rests when moving himself or herself around during daily activities and play time, 3) My child does enough activity so that he or she is breathing quickly or gets flushing in his or her face at least one time each day, and 4) My child spends a lot of his or her play or free time doing activities that require lots of physical energy. Parents rate each item on a scale from 1 (Never) to 5 (Always), with higher scores indicating greater endurance for activity. The average score for the four items is used for analysis. Acceptable test-retest reliability (ICC $=0.95$, 95\% $\mathrm{Cl}: 0.90-0.98)$ and validity of the 10 -item EASE have been reported with young children with $\mathrm{CP} .{ }^{10,13}$ Calculations from the same data for the 4-item EASE demonstrated acceptable but slightly lower testretest reliability $\left(\mathrm{ICC}=0.75(95 \% \mathrm{Cl} 0.54-0.87) \cdot{ }^{11}\right.$ The 4 -item and the 10 -item EASE have demonstrated a moderate correlation with the 6MWT $(r=0.52(p<.05) \text { and } r=0.57(P=.001) \text {, respectively })^{11}$ in a sample of 28 children ages 3 to 6 years of age ( 14 children without CP and 14 children with CP). In our previous work, confirmatory factor analysis indicated that the 4-item EASE captured the construct of endurance for activity well (Comparative fit index=0.998; Tucker Lewis Index $=0.993),{ }^{11}$ thus we chose to use it in this study to reduce the requested response burden on the parent. However, additional information on the reliability and validity of the 4-item EASE for older children is needed.

The Six Minute Walk Test $(6 \mathrm{MWT})^{14}$ is a test of submaximal walking endurance that has been used extensively in children and adults. The 6MWT has excellent test-retest reliability $($ ICC $=0.98), 2,15$ and reproduciblility $(r=0.87 ; P=.007$; intraclass correlation coefficient $[I C C]=0.80)$ and valid $(r=0.948 ; P<.001)$ in children with CP. ${ }^{16}$ It is often clinically used as a "capacity-based" measure (what child can do in an 
optimized clinical environment) of walking activity. Fitzgerald and colleagues ${ }^{17}$ published $6 \mathrm{MWT}$ reference values for children with spastic $\mathrm{CP}$ and children who were developing typically ages 4-17 years. They reported significant differences in children with CP classified in levels I-III on the Gross Motor Function Classification System (GMFCS) ${ }^{18}$ as compared with children developing typically.

The purpose of this study was to describe the EASE and 6MWT scores of young and school-aged children with CP by gross motor function classification level, sex, and age. We hypothesized that endurance and functional walking capacity would be higher in children with higher gross motor function, not differ by sex, and be higher in older children. We also examined the convergent validity of the EASE to the 6MWT scores to examine how closely these two measures are related. The results should provide evidence-based data to evaluate endurance and monitor change over time for children with CP.

Methods

This study was part of a multisite, prospective cohort study entitled 'On Track: Monitoring Development of Children with Cerebral Palsy and Gross Motor Delay,' which aimed to develop longitudinal developmental curves and reference percentiles for impairments, health conditions, and participation variables for children with cerebral palsy. The full study protocol, reported elsewhere, ${ }^{19}$ was reviewed and approved by the Institutional Review Boards (IRB) at all participating institutions and recruitment sites. All parents or guardians provided informed consent and children, as appropriate and in compliance with the specific IRB, provided assent. EASE and 6MWT data from the first assessment are analyzed and reported within this paper.

Participants

A convenience sample of 708 children with CP ages 18 -months up to the $12^{\text {th }}$ birthday at study onset, GMFCS Levels I-V participated in completing the EASE in this study. A smaller cohort of 376 of the 
study participants, ages 3 up to the child's $12^{\text {th }}$ birthday (mean $=82.0$ months, SD $=26.9$ months), GMFCS Levels I ( $n=176)$, II ( $n=138)$, and III ( $n=62)$ also participated in the 6MWT. Children were recruited from across Canada, including Ontario, Newfoundland, Manitoba, Alberta, and British Columbia, and four regions within the United States, including areas in and around, Georgia, Oklahoma, Pennsylvania, and Washington. Participating children had a diagnosis of CP by a physician or demonstrated delay in gross motor development in addition to impairments in: muscle tone, righting and equilibrium reactions, anticipatory postural movements of the head, trunk, or legs during movement, and active range of motion during movements. Children were excluded if their parents were unable to speak and understand English, French or Spanish. Demographic information of the children and their families is included in Table 1.

Procedure

At the initial On Track assessment session, the therapist and parent determined the child's GMFCS level via a consensus process. ${ }^{20}$ The GMFCS is a five-point classification system used to describe gross motor function ability in children with $\mathrm{CP} .{ }^{18}$ Distinctions between levels of the GMFCS are based on the need for assistive devices and caregiver assistance. Inter-rater reliability, content and construct validity, ${ }^{18}$ and stability ${ }^{21}$ of the GMFCS for use with children with CP has been supported in the literature. Additionally, the excellent reliability $(I C C=0.94)$ between therapist and family report for the GMFCS has also been established. ${ }^{22}$

Consensus on the GMFCS classification between the therapist and the parent was achieved 98.7\% of the time. In most cases where disagreements occurred, the parent's classification was used for analysis, and formal rules existed to determine instances where the assessor's classification should be used instead. ${ }^{20}$ These rules included situations where the assessor had written a compelling description of the child's capability that was lower than the parent-assigned GMFCS level, report of the use of the 
incorrect age band for the GMFCS leading to an inaccurate classification, or assessor report that the parent was not ready to participate in a discussion of consensus regarding GMFCS levels. ${ }^{20}$

The parents of all participants (GMFCS levels I-V) completed the EASE either online or within a parent booklet. The smaller cohort of 376 of the study participants also completed the 6MWT with trained and reliable therapist assessors. Assessors included 90 licensed physical and occupational therapists in the communities where the children resided. They participated in a training session prior to collecting data. For the 6MWT, the child was permitted to wear orthoses, if regularly used, and to use an assistive mobility device, selecting the device that allowed for the most sustained walking cadence or was typically be used for long walks. Assessors were instructed to select a walking course either indoors or outdoors on a large (about 100 feet), flat (no hills or bumps), hard terrain (asphalt, pavement) that would not require the child to make a 180-degree turn. The starting line was marked prior to beginning the $6 \mathrm{MWT}$, to allow for re-measurement, if needed. Standardized instructions were then used to describe the 6MWT to the child, encouraging the child to walk as far as he/she could in 6 minutes. The distance walked was measured using a calibrated measuring wheel, and a stopwatch was used to keep track of the allocated time. Assessors provided pre-established verbal encouragements to the child at each minute to encourage the child to keep going and do his/ her best. Conversations with the child were limited so as not to impact or slow the walking pace. Assessors recorded the total number of feet walked in 6-minutes.

\section{Data Analysis}

Descriptive data for the EASE and 6MWT distances were computed for children grouped by GMFCS level (I-V), by age (18-months to 3 years, 3 to 6 years, 6 to 9 years, and 9 to 11 years), and between boys and girls. Parametric statistics were used as the data demonstrated normal distributions. A two-way ANOVA examining GMFCS by age interactions was completed, showing interactions were not significant. Therefore, one-way ANOVA with post hoc Tukey tests were used to compare EASE scores 
and 6MWT distances among GMFCS levels and age groupings. Independent t-tests were used to examine differences between boys and girls. Convergent validity of the EASE and 6MWT was assessed using Pearson's r correlations for children classified as GMFCS levels I-III as a group and then individually by level.

Results

Descriptive statistics are presented in Table 2. Mean EASE scores differed based on children's GMFCS levels ( $p<.001)$ except between Levels II and III ( $p=.09)$. Higher EASE scores, representing greater perceived endurance for activity, were reported for children with higher gross motor function. Children aged 1.5- to 3-years and 3- to 6-years had significantly lower EASE scores than children 9- to 12-years $(p=.01$ and $p<.001$, respectively). No differences were noted between the other age groupings. EASE scores were not significantly different between boys and girls $(p=.11)$. See Figure 1 .

$<$ Insert Figure 1 about here $>$

On the 6MWT, children in GMFCS levels I, II, and III on average walked 1259.3 feet (383.8 meters), 922.0 feet (281.0 meters), and 545.8 feet (166.4 meters), respectively. Significant differences in distance walked were noted across all GMFCS levels I-III ( $p<.001)$. Differences in walking distance were noted across some of the age groupings $(p<.001)$. Children 3-6 years walked significantly less than children 6-9 years $(p<.001)$ and 9-11 years $(p<.001)$. No differences were noted in walking distance between children 6-9 and 9-11 years $(p=.29)$. Distance walked did not differ between girls and boys $(p=0.43)$. (See Figure 2).

$<$ Insert Figure 2 about here>

The EASE and 6MWT demonstrated a statistically significant but low, positive correlation ( $r=.30$, $\mathrm{p}<.001$ ) across GMFCS levels I-III, indicating that the EASE and 6MWT appear to measure different 
constructs. Correlations between the EASE and 6MWT by individual GMFCS levels demonstrated low, non-significant correlations of $r=.14$ for GMFCS level I, $r=.07$ for GMFCS level II, and $r=.02$ for GMFCS level III. (See Table 3)

$<$ Insert Table 3 about here>

\section{Discussion}

Parent perceived endurance for activity, as measured by the EASE, differed across GMFCS levels with higher EASE scores reported for children with higher gross motor function; however, parents of children in GMFCS Levels II and III reported similar perceived endurance. This finding is consistent with the results of initial construct validity testing on the original 10-item EASE completed by McCoy and colleagues ${ }^{10}$ who also reported significant differences across GMFCS levels $(p<.001)$, except between levels II and III ( $p=.62)$ for young children with CP. This may suggest that children in GMFCS levels II and III demonstrate similar endurance levels for activity, or that the EASE is not sensitive enough to detect the variations in endurance for activity between these two levels. Younger children, under 6-years of age, were reported to have higher endurance than children 9-12 years of age. This decrease in endurance in older children with $\mathrm{CP}$ has been frequently noted in the literature. ${ }^{6-8}$ EASE scores were not different between sexes, which is again consistent with the findings of McCoy and colleagues. ${ }^{10}$

Functional walking capacity, as measured by the 6MWT, increased based on children's walking ability, children classified in GMFCS level I (walks in all settings) walked a greater distance than children classified in GMFCS level II (difficulty walking long distances) or level III (walks with hand held mobility device). Children classified in GMFCS level II (difficulty walking long distances) walked a greater distance than children in GMFCS level III (walks with hand held mobility device). This finding is consistent with previous research that also reported significant differences across GMFCS levels, ${ }^{14,16}$ and may represent the increasing energy $\operatorname{cost}^{23}$ and physical demand associated with walking for children in levels II and III. 
Our hypothesis that walking capacity would increase with age was partially supported. Younger children in our sample (ages 3-6 years) walked significantly less distance than older children (ages 6-12 years). However, continued improvement in walking capacity was not noted between the two older groups of children. This finding may reflect that younger children with CP are still developing and refining their gross motor abilities, typically reaching their functional plateau by five years of age. ${ }^{24}$ As expected, there was no difference by sex.

The mean 6MWT distances in this study (GMFCS level I: 1259.3 feet (383.8 meters), GMFCS level II: 922.0 feet (281.0 meters), and GMFCS level III 545.8 feet (166.4 meters) are substantially lower than what was previously reported for children with CP. Thompson and colleagues ${ }^{14}$ reported mean distances of 486.6 meters, 312.9 meters, and 240.2 meters $4-18$ year old children with CP in GMFCS levels I, II, and III, respectively. Fitzgerald and colleagues ${ }^{17}$ reported mean distances of 439.57 meters, 386.74 meters, and 305.28 meters for 4-17 year old children with CP in GMFCS levels I, II, and III, respectively. These studies included children up to 17 or 18 years of age, which represents an older sample than examined in this current study, and this may account for some of the variations noted in the distances walked. The study walking distances may also have been impacted by the location of testing within the natural home or clinic environment, as opposed to within a standardized testing track used for all participants.

Additional research investigating these differences with an older sample of children is needed.

Scores on the EASE and 6MWT demonstrated a significant but low correlation across GMFCS level I-III and non-significant, low correlations when examining the GMFCS levels individually. This suggests that the EASE and 6MWT appear to assess different specific constructs associated with endurance for activity. The 6MWT is often used as a measure of functional walking capacity and may not clearly assess endurance for activity for children using a variety of forms of mobility rather than just walking. The EASE is a proxy measure for endurance for activity that is based on the parent's perception 
of the child's endurance ability, which introduces some variability in the measurement. For children in GMFCS levels I and II, the EASE may provide information related to general endurance for activity, but does not specifically capture walking capacity. The EASE also includes elements of frequency and intensity of a variety of physical activities, and may be a better measure for use with children at GMFCS levels III-V. Use of both measures may be important for children in GMFCS level III.

\section{Clinical Relevance}

We recommend therapists consider the impact of GMFCS level and age on endurance and functional walking capacity of children with CP and tailor intervention programs to specifically address these impairments. We also recommend therapists consider the use of standardized measures such as the EASE and 6MWT to assess and monitor endurance and functional walking capacity of children with $\mathrm{CP}$ to assist with appropriate intervention planning. Because of low convergent validity, consideration of the construct of interest is needed if choosing between the EASE and 6MWT for children with CP. Careful attention to preventing a decline in endurance and walking capacity may allow for increased participation in life activities for children with CP.

\section{Limitations}

Participants in this study were recruited as a sample of convenience, which presents a potential limitation; however, the GMFCS distribution of the larger On Track study participants is comparable to incidence data reported in the literature, supporting the applicability of the findings. ${ }^{26}$ Variations in the location of the $6 \mathrm{MWT}$, due to weather or family relocation, and testing within the natural environment may have impacted the distance walked for some children. Additionally, this study investigated the shorter 4-item EASE, as opposed to the 10-item EASE, which demonstrated moderate correlation to the 6MWT in our previous work. ${ }^{10}$ More research is needed to determine the reliability and validity of the EASE in older children. 
Conclusion

Children with CP present with variations in endurance and functional walking capacity based on GMFCS level and, to a lesser extent, age. The EASE and 6MWT are standardized assessments measuring two different constructs, endurance and walking capacity respectively, which provide clinicians with information that contributes to a comprehensive assessment of a child's functional abilities.

Understanding the relationship between these outcomes and GMFCS levels and age, assists clinicians with setting goals and creating intervention programs targeted at improving endurance for activity and functional walking capacity. Children with $\mathrm{CP}$ who have greater endurance are afforded more opportunities for participation in the community. As therapists develop intervention programs, careful attention to monitoring and preventing a decline in endurance and walking capacity may allow for increased participation in life activities for children with CP.

\section{References}

1. van den Berg-Emons HJ, Saris WH, de Barbanson DC, Westerterp KR, Huson A, van Baak MA. Daily physical activity of schoolchildren with spastic diplegia and of healthy control subjects. $J$ Pediatr. 1995; 127:578-584.

2. Maher CA, Williams MT, Olds TS. The six-minute walk test for children with cerebral palsy. Internat J Rehabil Res. 2008;31:185-188.

3. Caspersen CJ, Powell KE, Christenson GM. Physical activity, exercise and physical fitness: definitions and distinctions for health-related research. Public Health Rep. 1985; 100: 126-131.

4. Rimmer JH. Physical fitness levels of persons with CP. Dev Med Child Neurol. 2001;43:208 -212.

5. Damiano DL. Strength, endurance and fitness in CP. Quebec Abstr. 2003;8-10.

6. Maltais DB, Pierrynowski MR, Galea VA, Bar-Or O. Physical activity level is associated with $\mathrm{O}_{2}$ cost of walking in cerebral palsy. Med Sci Sports Exerc. 2005;37:347-353.

7. Johnston TE, Moore SE, Quinn LT, Smith BT. Energy cost of walking in children with cerebral palsy: relation to the Gross Motor Function Classification System. Dev Med Child Neurol. 2004;46:34-38. 
8. Johnson DD, Damiano DL, Abel MF. The evolution of gait in childhood and adolescent cerebral palsy. J Pediatr Orthop. 1997; 17:392-396.

9. Fauconnier J, Dickinson HO, Beckung E, et al. Participation in life situations of 8-12 year old children with cerebral palsy: cross sectional European study BMJ. 2009; 338 :b1458

10. McCoy SW, Yocum A, Bartlett DJ, et al. Development of the Early Activity Scale for Endurance for children with cerebral palsy. Pediatr Phys Ther. 2012; 24:232-240.

11. Mendoza JM, McCoy SW, Zygmuntowicz E, Kevan B, Katsel E, Move and PLAY team. Reliability and validity of an endurance questionnaire in young children with cerebral palsy. Pediatr Phys Ther. 2010;22:128.

12. ATS statement: guidelines for the six-minute walk test. ATS Committee on Proficiency Standards for Clinical Pulmonary Function Laboratories. Am J Respir Crit Care Med 2002; 166: 111-117.

13. Jeffries L, Fiss AL, McCoy SW, Bartlett DJ. Description of primary and secondary impairments in young children with cerebral palsy. Pediatr Phys Ther. 2016;28:7-14.

14. ATS statement: guidelines for the six-minute walk test. ATS Committee on Proficiency Standards for Clinical Pulmonary Function Laboratories. Am J Respir Crit Care Med 2002; 166: 111-117.

15. Thompson P, Beath T, Bell J, et al. Test-retest reliability of the 10-metre fast walk test and 6minute walk test in ambulatory school-aged children with cerebral palsy. Dev Med Child Neurol. 2008;50(5):370-376.

16. Nsenga Leunkeu A, Shephard RJ, Ahmaidi S. Six-minute walk test in children with cerebral palsy Gross Motor Function Classification System levels I and II: reproducibility, validity, and training effects. Arch Phys Med Rehabil. 2012;93:2333-2339.

17. Fitzgerald D, Hickey C, Delahunt E, Walsh M, O'Brien T. Six-minute walk test in children with spastic cerebral palsy and children developing typically. Pediatr Phys Ther. 2016; 28:192-199.

18. Palisano R, Rosenbaum $P$, Bartlett $D$, Livingston $M$. Content validity of the expanded and revised Gross Motor Function Classification System. Dev Med Child Neurol. 2008; 50:744-750.

19. McCoy SW, Bartlett D, Smersh M, Galuppi B, Hanna S, Collaboration Group: On Track Study Team. Monitoring development of children with cerebral palsy: the On Track study. Protocol of a longitudinal study of development and services. Available at:

https://www.canchild.ca/en/resources/294-monitoring-development-of-children-with-cerebralpalsy-the-on-track-study-protocol-of-a-longitudinal-study-of-development-and-services.

Accessed March 21, 2018.

20. Bartlett DJ, Galuppi B, Palisano RJ, McCoy SW. Consensus classifications of gross motor, manual ability, and communication function classification systems between therapists and parents of children with cerebral palsy. Dev Med Child Neurol. 2016; 58:98-99. 
21. Alriksson-Schmidt A, Nordmark E, Czuba T, Westbom L. Stability of the Gross Motor Function Classification System in children and adolescents with cerebral palsy: a retrospective cohort registry study. Dev Med Child Neurol. 2017;59:641-646.

22. Morris C, Galuppi BE, Rosenbaum PL. Reliability of family report for the Gross Motor Function Classification System. Dev Med Child Neurol. 2004;46:455-460.

23. Johnston TE, Moore ST, Quinn LT, Smith B. Energy cost of walking in children with cerebral palsy: Relation to the Gross Motor Function Classification System. Dev Med Child Neurol. 2004;46:34-8.

24. Rosenbaum PL, Walter SD, Hanna SE, et al. Prognosis for gross motor function in cerebral palsy: creation of motor development curves. JAMA. 2002;288:1357-1363.

25. Klepper SE, Muir N. Reference values on the 6-minute walk test for children living in the United States. Pediatr Phys Ther. 2011; 23:32-40.

26. Reid SM, Carlin JB, Reddihough DS. Using the Gross Motor Function Classification System to describe patterns of motor severity in cerebral palsy. Dev Med Child Neurol. 2011; 53:10071012. 
Figure 1. EASE Comparisons
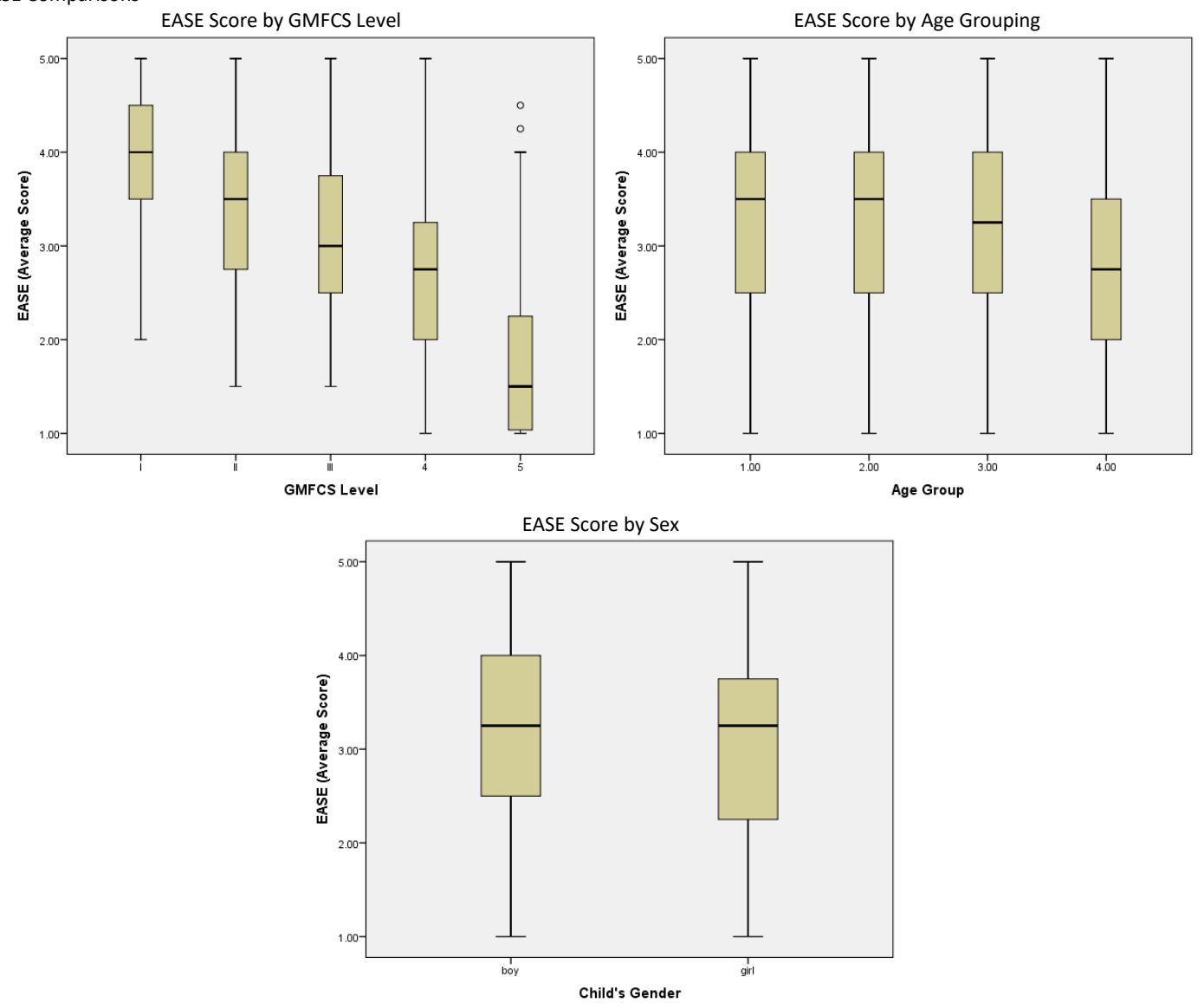
Figure 2. 6MWT Comparison
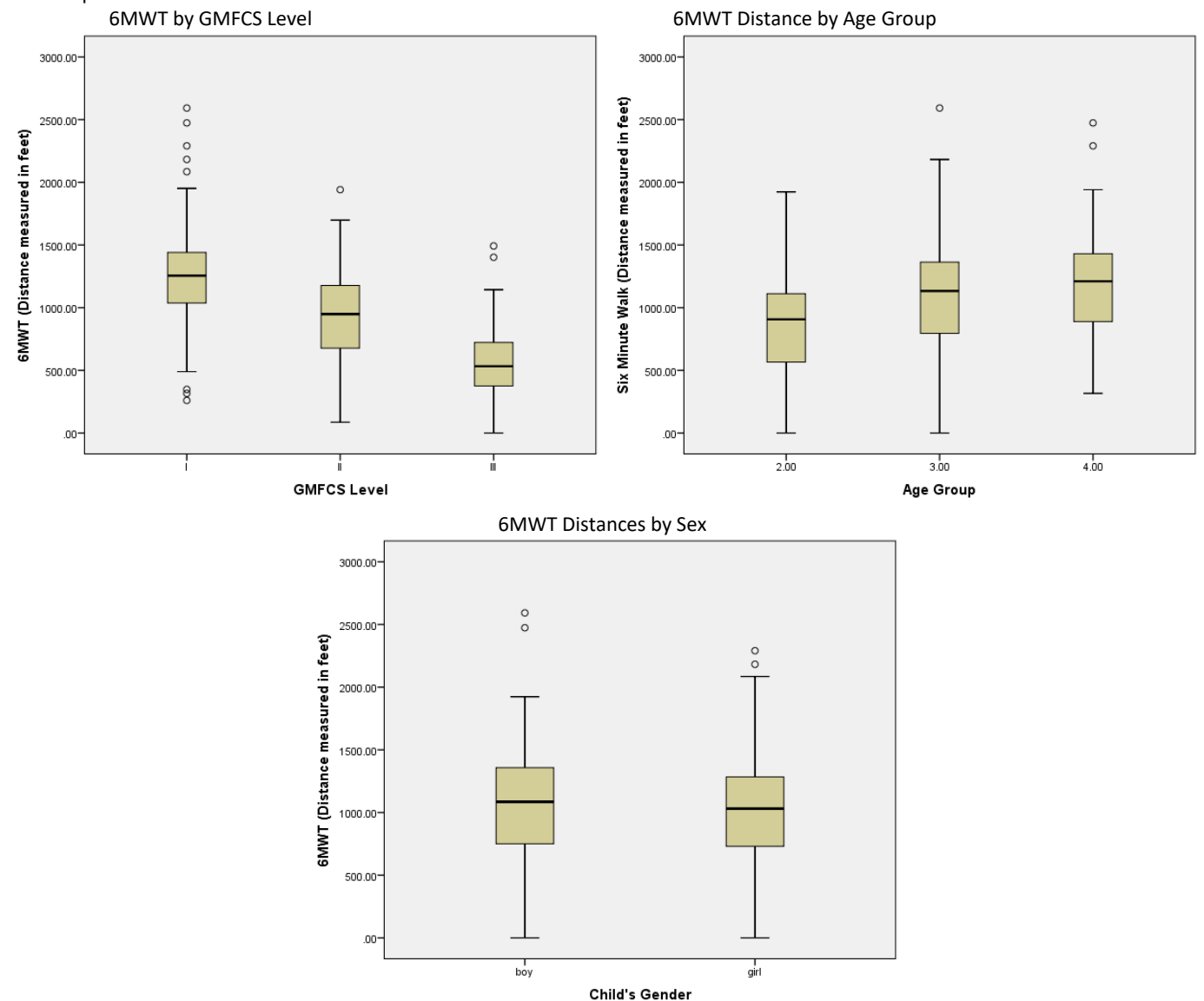

Table 1. Child and Parent Demographics

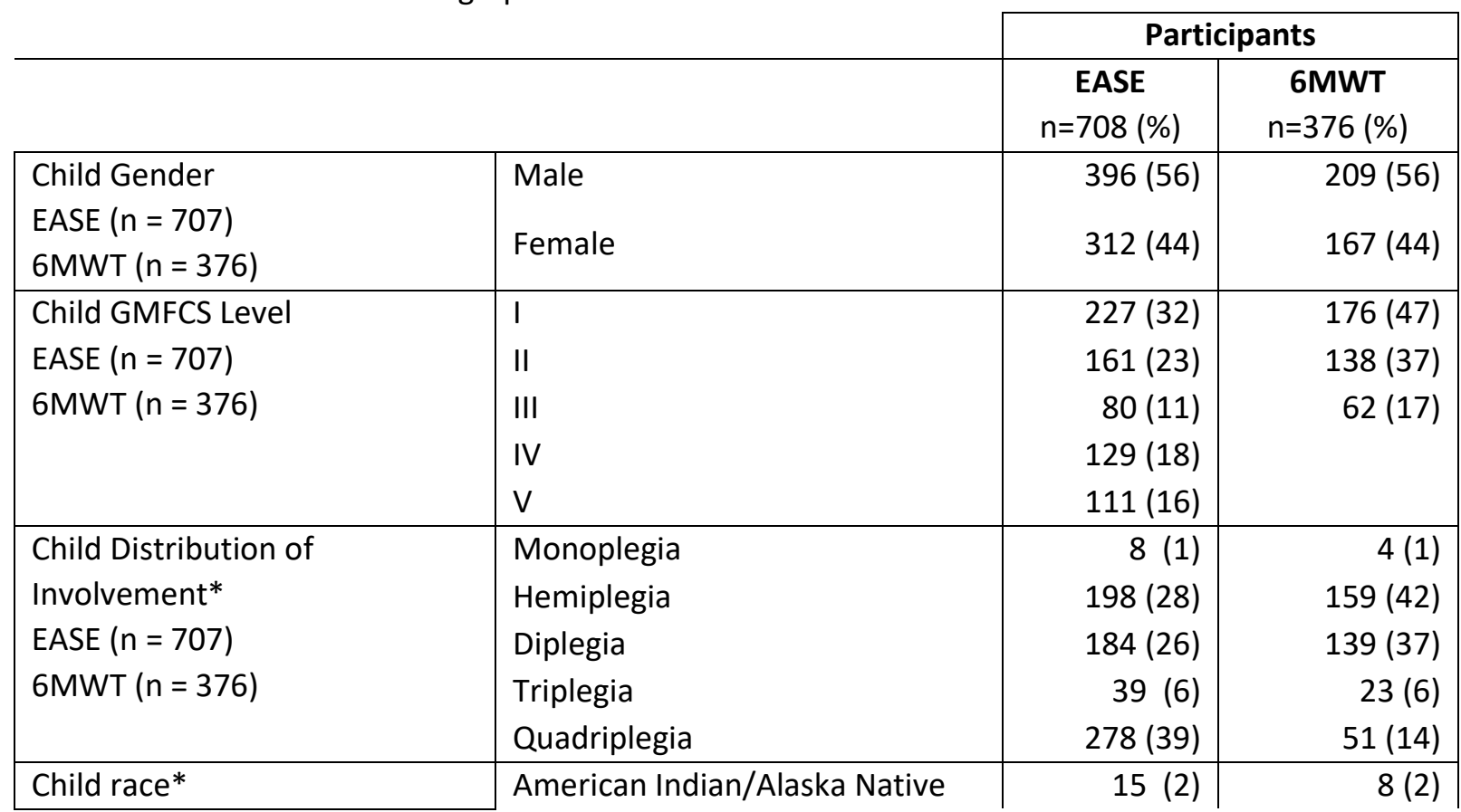




\begin{tabular}{|c|c|c|c|}
\hline $\begin{array}{l}\text { EASE }(n=699) \\
6 M W T(n=368)\end{array}$ & $\begin{array}{l}\text { Asian } \\
\text { Black/African American } \\
\text { White } \\
\text { Multi }\end{array}$ & $\begin{array}{r}40(6) \\
60(8) \\
503(72) \\
81(12)\end{array}$ & $\begin{array}{r}23(6) \\
25(6) \\
276(74) \\
36(10)\end{array}$ \\
\hline $\begin{array}{l}\text { Child ethnicity* } \\
\text { EASE }(n=703) \\
6 \text { MWT }(n=372)\end{array}$ & $\begin{array}{l}\text { Hispanic } \\
\text { Non-Hispanic } \\
\text { Aboriginal } \\
\text { Non-Aboriginal }\end{array}$ & $\begin{array}{r}49(7) \\
654(93) \\
31(4) \\
672(96)\end{array}$ & $\begin{array}{r}26(7) \\
346(92) \\
357(95) \\
16(4)\end{array}$ \\
\hline $\begin{array}{l}\text { Parent respondent race* } \\
\text { EASE }(n=698) \\
6 M W T(n=369)\end{array}$ & $\begin{array}{l}\text { American Indian/Alaska Native } \\
\text { Asian } \\
\text { Black/African American } \\
\text { White } \\
\text { Multi }\end{array}$ & $\begin{array}{r}15(2) \\
51(7) \\
56(8) \\
550(79) \\
26(4)\end{array}$ & $\begin{array}{r}9(2) \\
26(7) \\
21(6) \\
302(80) \\
11(3)\end{array}$ \\
\hline $\begin{array}{l}\text { Parent respondent ethnicity* } \\
\text { EASE }(n=701) \\
6 M W T(n=371)\end{array}$ & $\begin{array}{l}\text { Hispanic } \\
\text { Non-Hispanic } \\
\text { Aboriginal } \\
\text { Non-Aboriginal }\end{array}$ & $\begin{array}{r}32(5) \\
669(95) \\
20(3) \\
681(97)\end{array}$ & $\begin{array}{r}16(4) \\
355(94) \\
10(3) \\
361(96)\end{array}$ \\
\hline $\begin{array}{l}\text { Parent respondent age, years* } \\
\text { EASE }(n=694) \\
6 \text { MWT }(n=367)\end{array}$ & Mean (SD) & 37.8 (7.9) & $38.6(7.8)$ \\
\hline $\begin{array}{l}\text { Parent respondent relationship } \\
\text { to child* } \\
\text { EASE }(n=704) \\
6 \text { MWT }(n=373)\end{array}$ & $\begin{array}{l}\text { Mother } \\
\text { Father } \\
\text { Other }\end{array}$ & $\begin{array}{r}628(89) \\
51(7) \\
25(4)\end{array}$ & $\begin{array}{r}330(88) \\
33(9) \\
10(3)\end{array}$ \\
\hline $\begin{array}{l}\text { Parent respondent education* } \\
\text { EASE }(n=700) \\
6 M W T(n=370)\end{array}$ & $\begin{array}{l}\text { High School or less } \\
\text { Community College / Associate's } \\
\text { Degree } \\
\text { University }\end{array}$ & $\begin{array}{l}160(23) \\
212(30) \\
328(47)\end{array}$ & $\begin{array}{r}66(18) \\
122(32) \\
179(48)\end{array}$ \\
\hline $\begin{array}{l}\text { Family Income* } \\
\text { EASE }(n=594) \\
6 \text { MWT }(n=307)\end{array}$ & $\begin{array}{l}\geq \$ 75,000 \\
\$ 60,000-\$ 74,999 \\
\$ 45,000-\$ 59,999 \\
\$ 30,000-\$ 44,999 \\
\leq \$ 30,000\end{array}$ & $\begin{array}{r}306(52) \\
78(13) \\
50(8) \\
58(10) \\
102(17)\end{array}$ & $\begin{array}{r}170(55) \\
40(13) \\
23(8) \\
24(8) \\
50(16)\end{array}$ \\
\hline $\begin{array}{l}\text { Country } \\
\text { EASE }(n=708) \\
6 M W T(n=373)\end{array}$ & $\begin{array}{l}\text { Canada } \\
\text { United States }\end{array}$ & $\begin{array}{l}347(49) \\
361(51)\end{array}$ & $\begin{array}{l}192(51) \\
184(49)\end{array}$ \\
\hline
\end{tabular}


SD = standard deviation

* report based on the available information

Notes: 'mother' includes mother, adoptive mother, foster mother, or custodial mother; 'father' includes father, adoptive father, or step father; 'other' includes grandparent, nursing supervisor, or aunt.

Table 2. Mean EASE Scores and 6MWT Distances and Pairwise Comparisons

\begin{tabular}{|c|c|c|c|}
\hline \multicolumn{4}{|l|}{ EASE } \\
\hline GMFCS & Mean (SD) & Comparison & $\mathrm{p}$-value \\
\hline $\begin{array}{l}\text { Level I } \\
(n=227)\end{array}$ & $3.9(.7)$ & $\begin{array}{l}\text { Level II } \\
\text { Level III } \\
\text { Level IV } \\
\text { Level V }\end{array}$ & $\begin{array}{l}<.001 \\
<.001 \\
<.001 \\
<.001\end{array}$ \\
\hline $\begin{array}{l}\text { Level II } \\
(n=161)\end{array}$ & $3.4(.8)$ & $\begin{array}{l}\text { Level III } \\
\text { Level IV } \\
\text { Level V }\end{array}$ & $\begin{array}{l}.09 \\
<.001 \\
<.001 \\
\end{array}$ \\
\hline $\begin{array}{l}\text { Level III } \\
(n=80)\end{array}$ & $3.1(.8)$ & $\begin{array}{l}\text { Level IV } \\
\text { Level V }\end{array}$ & $\begin{array}{l}.01 \\
<.001\end{array}$ \\
\hline $\begin{array}{l}\text { Level IV } \\
(n=129)\end{array}$ & $2.7(.9)$ & Level V & $<.001$ \\
\hline $\begin{array}{l}\text { Level V } \\
(n=111)\end{array}$ & $1.8(.9)$ & & \\
\hline Age & Mean (SD) & Comparison & $\mathrm{p}$-value \\
\hline $\begin{array}{l}18 \text { months }-3 \text { years } \\
(n=131)\end{array}$ & $3.3(1.1)$ & $\begin{array}{l}3-6 \text { years } \\
6-9 \text { years } \\
9-12 \text { years }\end{array}$ & $\begin{array}{l}.99 \\
.33 \\
.01 \\
\end{array}$ \\
\hline $\begin{array}{l}\text { 3-6 years } \\
(n=216)\end{array}$ & $3.3(1.0)$ & $\begin{array}{l}6-9 \text { years } \\
9-12 \text { years } \\
\end{array}$ & $\begin{array}{l}.11 \\
.001 \\
\end{array}$ \\
\hline $\begin{array}{l}6-9 \text { years } \\
(n=246)\end{array}$ & $3.1(1.0)$ & $9-12$ years & .17 \\
\hline $\begin{array}{l}9-12 \text { years } \\
(n=115)\end{array}$ & $2.9(1.0)$ & & \\
\hline Sex & Mean (SD) & Comparison & $\mathrm{p}$-value \\
\hline $\begin{array}{l}\text { Male } \\
(n=396)\end{array}$ & $3.2(1.1)$ & Female & .11 \\
\hline $\begin{array}{l}\text { Female } \\
(n=312) \\
\end{array}$ & $3.1(1.1)$ & & \\
\hline \multicolumn{4}{|l|}{ 6MWT } \\
\hline GMFCS & $\begin{array}{l}\text { Mean (SD) in feet } \\
\text { Mean (SD) in meters }\end{array}$ & Comparison & $p$-value \\
\hline $\begin{array}{l}\text { Level I } \\
(n=176)\end{array}$ & $\begin{array}{l}1259.3(349.3) \\
383.8(106.5)\end{array}$ & $\begin{array}{l}\text { Level II } \\
\text { Level III }\end{array}$ & $\begin{array}{l}<.001 \\
<.001\end{array}$ \\
\hline Level II & $922.0(358.1)$ & Level III & $<.001$ \\
\hline
\end{tabular}




\begin{tabular}{|l|l|l|l|}
\hline$(n=138)$ & $281.0(109.2)$ & & \\
\hline $\begin{array}{l}\text { Level III } \\
(n=62)\end{array}$ & $545.8(324.9)$ & & \\
\hline Age & $166.4(99.0)$ & & \\
& $\begin{array}{l}\text { Mean (SD) in feet } \\
\text { Mean (SD) in meters }\end{array}$ & Comparison & \\
\hline $\begin{array}{l}3-6 \text { years } \\
(n=141)\end{array}$ & $852.9(397.1)$ & $6-9$ years & \\
\hline $\begin{array}{l}6-9 \text { years } \\
(n=157)\end{array}$ & $260.0(121.0)$ & $9-12$ years & $<.001$ \\
\hline $\begin{array}{l}9-12 \text { years } \\
(n=78)\end{array}$ & $1088.2(423.6)$ & $9-12$ years & .001 \\
\hline Sex & $332.0(129.1)$ & & .29 \\
\hline $\begin{array}{l}\text { Male } \\
(n=209)\end{array}$ & $358.0(130.4(428.1)$ & & \\
\hline Female \\
$(n=167)$
\end{tabular}

Table 3. Correlations Between the 6MWT Distances and EASE Scores

\begin{tabular}{|lll|}
\hline GMFCS (n) & Pearson $r$ & -value \\
\hline Level I (176) & .14 & .06 \\
Level II (138) & .07 & .44 \\
Level III (62) & .02 & .88 \\
Total & .30 & $\mathrm{P}<.001^{*}$ \\
\hline
\end{tabular}

* Indicates significance at $p>.05$ level 